\author{
Lars B. Holst \\ Jeffrey L. Carson \\ Anders Perner
}

\section{Should red blood cell transfusion be individualized? No}

Received: 22 June 2015

Accepted: 23 June 2015

Published online: 7 July 2015

(C) Springer-Verlag Berlin Heidelberg and ESICM 2015

For a contrasting viewpoint, please go to

doi:10.1007/s00134-015-3950-7.

L. B. Holst · A. Perner (-)

Department of Intensive Care, Rigshospitalet, University of

Copenhagen, Copenhagen, Denmark

e-mail: anders.perner@ regionh.dk

L. B. Holst

e-mail: lars.broksoe.holst@regionh.dk

\section{J. L. Carson}

Division of General Internal Medicine, Department of Medicine, Rutgers Robert Wood Johnson Medical School, New Brunswick, NJ, USA

e-mail: jeffrey.carson@ rutgers.edu

\section{Introduction}

Red blood cell (RBC) transfusion practice has changed over recent decades with the use of still more restrictive strategy in agreement with revised clinical guidelines and increased focus on the concept of blood management [1]. The developments have raised the question if there are subgroups of patients, in particular among the critically ill, who may benefit from an individualized transfusion strategy.

\section{Current critical care practice and its evidence base}

The primary driver of RBC transfusions, the transfusion trigger, in critical care is likely to be hemoglobin $(\mathrm{Hb})$ values $[2,3]$. All the major RBC transfusion trials have compared restrictive to liberal strategies based on higher vs. lower $\mathrm{Hb}$ thresholds for transfusion [4-6]. This is also true for the five trials in the ICU setting [7-11] including a total of 2639 patients. In all five trials $\mathrm{Hb}$ of $7 \mathrm{~g} / \mathrm{dl}$ was used as the lower transfusion threshold and none of the trials showed harm with the use of this threshold. Metaanalysis of the five trials examining mortality at the longest follow-up time period indicated no heterogeneity and that using $7 \mathrm{~g} / \mathrm{dl}$ vs. a higher threshold had no effect on mortality [relative risk (RR) $0.92,95 \%$ confidence interval (CI) 0.82-1.03] (Fig. 1). All five trials showed that using $\mathrm{Hb}$ of $7 \mathrm{~g} / \mathrm{dl}$ compared to a higher threshold reduced the number of RBC units transfused and the number of patients being transfused. The results in the critical care setting are in line with the general

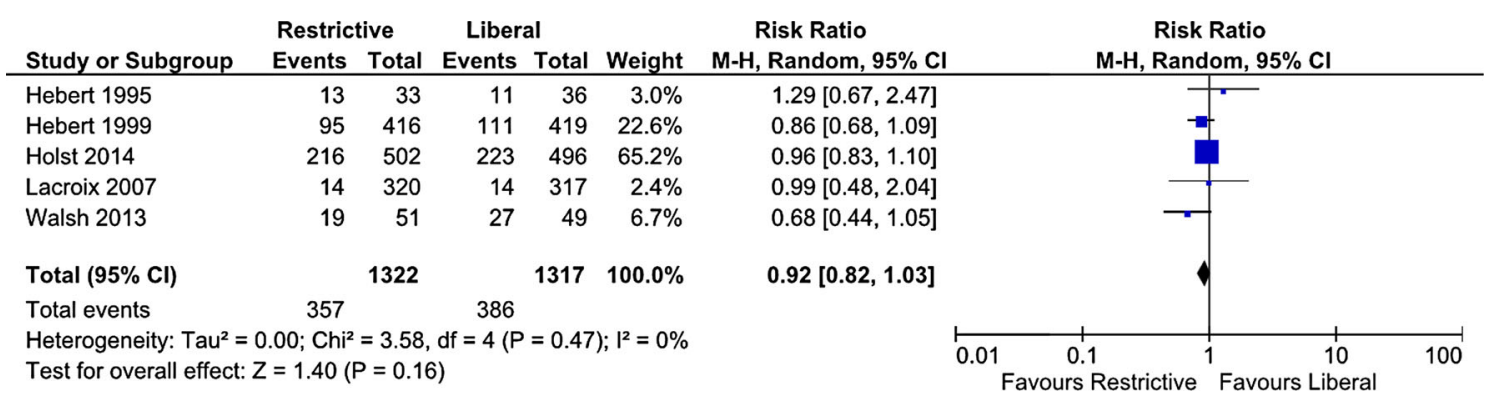

Fig. 1 Meta-analysis of the effect on mortality of higher vs. lower hemoglobin thresholds for RBC transfusion in randomized clinical trials in ICU patients. In all trials $7 \mathrm{~g} / \mathrm{dl}$ was used as the lower threshold for transfusion 
recommendations of $\mathrm{Hb}$ of $7-8 \mathrm{~g} / \mathrm{dl}$ as the 'universal' trigger level for transfusion [1].

Three groups of patients may need special consideration, namely those with acute myocardial ischemia, acute brain injury, and those undergoing elective cardiac surgery.

\section{Patients with acute myocardial ischemia}

A meta-analysis including both observational studies and randomized trials indicated harm [RR 2.04 (95\% CI 1.06-3.93)] with liberal transfusion strategies or transfusion as compared to restrictive transfusion strategy or no transfusion, but the observational data in this particular setting are likely to be biased and suffer from uncontrolled confounding [12]. To date only two small randomized controlled trials (RCTs) including a total of 155 patients have compared lower vs. higher Hb thresholds for transfusion in patients with acute myocardial infarction [13, 14]. Therefore, we urgently need highquality trials of lower vs. higher $\mathrm{Hb}$ thresholds for $\mathrm{RBC}$ transfusion in this patient group.

\section{Patients with acute brain injury}

Few trials have randomized patients with traumatic brain injury $[15,16]$. In the latest published RCT a factorial design was used to randomize 200 patients with closed head injury $\mathrm{Hb}$ values of 7 vs. $10 \mathrm{~g} / \mathrm{dl}$ for RBC transfusion and to erythropoietin vs. placebo [16]. Glasgow Outcome Score at 6 months was comparable in the two transfusion groups. However, there were fewer thromboembolic complications in the restrictive group.

\section{Patients undergoing elective cardiac surgery}

A recent high-quality RCT compared the use of an $\mathrm{Hb}$ threshold for transfusion of $7.5 \mathrm{vs.} 9 \mathrm{~g} / \mathrm{dl}$ in 2007 patients undergoing elective cardiac surgery. There was no difference in the primary outcome (composite serious infections or ischemic events), 30-day mortality, or any other outcome measure except for 90-day mortality, which was higher in the restrictive group $(P=0.045)$ [6]. It is still unclear if the latter was a chance finding and the results have not yet been incorporated into meta-analyses.

\section{Individualization of transfusion based on alternative triggers}

Markers of hypoperfusion together with $\mathrm{Hb}$ values might be useful to guide blood transfusion. Abnormal values of venous oxygen saturation $\left(\mathrm{SvO}_{2}\right)$, blood lactate concentration, or ST segment dynamics may identify patients that may benefit from RBC transfusion at higher Hb levels. In early septic shock, the combination of low $\mathrm{SvO}_{2}$ and hematocrit has been recommended as a trigger of transfusion, but the value of this composite trigger is now being questioned after publication of the ProCESS, ARISE, and ProMISe trials showing no effect on mortality when used as part of a complex protocol including higher RBC transfusion rates [17]. None of the other markers have been assessed in high-quality trials and patient symptoms (e.g., dizziness, fatigue, and orthostatic intolerance) are often less useful in the critical care setting. Taken together, there are no high-quality data supporting additional triggers to $\mathrm{Hb}$ values for RBC transfusion in critically ill patients.

\section{Blood transfusion should not be individualized in the majority of critically ill patients}

For the majority of critical care patients there is no highquality evidence supporting individualized RBC transfusion. A restrictive RBC transfusion strategy appears safe and results in reduced use of RBCs and fewer patients being transfused. Thus, a $\mathrm{Hb}$ threshold of $7 \mathrm{~g} / \mathrm{dl}$ should be regarded as the "new normal" [18] in the critical care setting, but further consideration may be needed in patients with myocardial infarction, acute brain injury, and those undergoing elective cardiac surgery.

Conflicts of interest The authors have no relevant conflicts of interests.

\section{References}

1. Carson JL, Grossman BJ, Kleinman S et al (2012) Red blood cell transfusion: a clinical practice guideline from the AABB. Ann Intern Med 157:49-58
2. Vincent JL, Baron J-F, Reinhart K et al (2002) Anemia and blood transfusion in critically ill patients. JAMA 288:1499-1507
3. Rosland RG, Hagen MU, Haase $\mathrm{N}$ et al (2014) Red blood cell transfusion in septic shock - clinical characteristics and outcome of unselected patients in a prospective, multicentre cohort. Scand J Trauma Resusc Emerg Med 22:14 
4. Carson JL, Terrin ML, Novchek MPH, Sanders DW (2011) Liberal or restrictive transfusion in high-risk patients after hip surgery. N Engl J Med 365:2453-2462

5. Villanueva C, Colomo A, Bosch A et al (2013) Transfusion strategies for acute upper gastrointestinal bleeding. N Engl J Med 368:11-21

6. Murphy GJ, Pike K, Rogers $\mathrm{C}$ a et al (2015) Liberal or restrictive transfusion after cardiac surgery. N Engl J Med 372:997-1008

7. Hebert PC, Wells G, Marshall J, Martin $C$ et al (1995) Transfusion requirements in critical care. A pilot study. JAMA 273:1439-1444

8. Hébert P, Wells G, Blajchman MA, Marshall JC (1999) A multicenter, randomized, controlled clinical trial of transfusion requirements in critical care. N Engl J Med 340:409-417

9. Lacroix J, Hébert PC, Hutchison JS, Hume HA (2007) Transfusion strategies for patients in pediatric intensive care units. N Engl J Med 356:1609-1619
10. Walsh TS, Boyd JA, Watson D et al (2013) Restrictive versus liberal transfusion strategies for older mechanically ventilated critically ill patients: a randomized pilot trial. Crit Care Med 41:1-10

11. Holst LB, Haase N, Wetterslev J et al (2014) Lower versus higher hemoglobin threshold for transfusion in septic shock. N Engl J Med 371:1381-1391

12. Chatterjee S, Wetterslev J, Sharma A et al (2013) Association of blood transfusion with increased mortality in myocardial infarction: a meta-analysis and diversity-adjusted study sequential analysis. JAMA Intern Med 173:132-139

13. Cooper HA, Rao SV, Greenberg MD et al (2011) Conservative versus liberal red cell transfusion in acute myocardial infarction (the CRIT randomized pilot study). Am J Cardiol 108:1108-1111
14. Carson JL, Brooks MM, Abbott JD et al (2013) Liberal versus restrictive transfusion thresholds for patients with symptomatic coronary artery disease. Am Heart J 165:964-971

15. Zygun DA, Nortje J, Hutchinson PJ et al (2009) The effect of red blood cell transfusion on cerebral oxygenation and metabolism after severe traumatic brain injury. Crit Care Med 37:1074-1078

16. Robertson CS, Hannay HJ, Yamal J-M et al (2014) Effect of erythropoietin and transfusion threshold on neurological recovery after traumatic brain injury. JAMA 312:36

17. Angus DC, Barnato a. E, Bell D, et al. (2015) A systematic review and metaanalysis of early goal-directed therapy for septic shock: the ARISE, ProCESS and ProMISe Investigators. Intensive Care Med. doi: 10.1007/s00134-015-3822-1

18. Hébert PC, Carson JL (2014) Transfusion threshold of $7 \mathrm{~g}$ per deciliter-the new normal. N Engl J Med 371:1459-1461 